\title{
Editorial
}

\section{High Time for High-Flux Hemodialysis Mechanistic Studies}

\author{
Jonas Axelsson \\ Department of Clinical Science, Intervention and Technology, Karolinska Institutet, Stockholm, Sweden
}

In the current issue of Blood Purification, Dr. Chu and co-workers present their study 'The Effects of Low-Flux and High-Flux Dialyzers on Oxidative Stress and Insulin Resistance', showing an almost 50\% reduction in insulin resistance (as assessed using HOMA-IR) in 20 patients randomized to 2 months of high-flux hemodialysis (HD). In contrast, 18 patients randomized to receive low-flux HD showed no reduction of insulin resistance.

After the HEMO trial [1] (the largest randomized and controlled trial to date designed to compare high- and low-flux HD) concluded that patients undergoing HD three times weekly appeared to have no benefit from the use of a high-flux membrane, many nephrologists despaired. If a larger dialysis dose and higher middle molecule removal were not of benefit to our patients, what was? However, subsequent analysis of the HEMO dataset [2] as well as other large datasets, including the USRDS [3] and the 4D Study [4], have all pointed to a potential lowering of both cerebrovascular and cardiovascular mortality in patients receiving high-flux dialysis. Perhaps of even greater interest, the recently finished MPO Study, not published yet but reported at both the EDTA 2007 and ASN 2007, shows a survival benefit for highflux dialysis in incident European dialysis patients with $\mathrm{S}$-albumin below $4 \mathrm{~g} / \mathrm{dl}$ and not reusing their dialyzers.

While not designed to show any effect on mortality, the present study by Chu et al. adds to the small but growing body of mechanistic data supporting a beneficial ef- fect of high-flux HD. Indeed, the HEMO Study showed that increasing small molecule removal does not appear to affect outcome [1]. Instead, more and more interest has focused on the ability of high-flux filters to remove middle molecules known to be associated with disease in uremia [5], including $\beta_{2}$-microglobulin [6]. Indeed, the healthy kidney is likely an important organ for the metabolism of insulin and putatively also of other signaling molecules [7], while uremia is associated with markedly elevated levels of most cytokines and adipokines [8]. Thus, much needs to be done to understand the pathophysiological role of altered renal metabolism of middle molecules and polypeptides in the context of uremia and renal replacement therapy. Encouragement for this type of research may be found in a recent study by Haase et al. [9], who showed clearance rates of $14-75 \mathrm{ml} / \mathrm{min}$ for a number of cytokines during intermittent HD using a membrane with extended permeability in 10 septic patients with acute renal failure.

In conclusion, while validation of high-flux HD will remain the target of large, randomized and controlled trials, better understanding of what can be achieved with more permeable membranes in relation to the physiology of the healthy kidney will greatly aid us in selecting patients and outcomes to study in randomized and controlled trials. There is indeed a too low flux of mechanistic studies of high-flux dialysis!

\section{KARGER \\ Fax +41613061234 \\ E-Mail karger@karger.ch \\ www.karger.com \\ (c) 2008 S. Karger AG, Basel \\ $0253-5068 / 08 / 0262-0211 \$ 24.50 / 0$ \\ Accessible online at: \\ www.karger.com/bpu}

Jonas Axelsson

Division of Renal Medicine

Department of Clinical Science, Intervention, and Technology, Karolinska Institutet SE-14186 Stockholm (Sweden)

Tel. +46 858583 981, Fax +46858583 925, E-Mail jonas.axelsson@ki.se 


\section{References}

-1 Eknoyan G, Beck GJ, Cheung AK, Daugirdas JT, et al: Effect of dialysis dose and membrane flux in maintenance hemodialysis. $\mathrm{N}$ Engl J Med 2002;347:2010-2019.

$>2$ Delmez JA, Yan G, Bailey J, Beck GJ, et al: Cerebrovascular disease in maintenance hemodialysis patients: results of the HEMO Study. Am J Kidney Dis 2006;47:131-138.

3 Port FK, Wolfe RA, Hulbert-Shearon TE, Daugirdas JT, et al: Mortality risk by hemodialyzer reuse practice and dialyzer membrane characteristics: results from the USRDS Dialysis Morbidity and Mortality Study. Am J Kidney Dis 2001;37:276-286.
4 Krane V, Krieter DH, Olschewski M, Marz W, et al: Dialyzer membrane characteristics and outcome of patients with type 2 diabetes on maintenance hemodialysis. Am J Kidney Dis 2007;49:267-275.

5 Leypoldt JK, Cheung AK, Carroll CE, Stannard DC, et al: Effect of dialysis membranes and middle molecule removal on chronic hemodialysis patient survival. Am J Kidney Dis 1999;33:349-355.

6 Cheung AK, Rocco MV, Yan G, Leypoldt JK, et al: Serum $\beta_{2}$-microglobulin levels predict mortality in dialysis patients: results of the HEMO Study. J Am Soc Nephrol 2006;17: 546-555.
7 Axelsson J, Bergsten A, Qureshi AR, Heimburger $\mathrm{O}$, et al: Elevated resistin levels in chronic kidney disease are associated with decreased glomerular filtration rate and inflammation, but not with insulin resistance. Kidney Int 2006;69:596-604.

8 Kalantar-Zadeh K: Inflammatory marker mania in chronic kidney disease: pentraxins at the crossroad of universal soldiers of inflammation. Clin J Am Soc Nephrol 2007;2: 872-875.

$\checkmark 9$ Haase M, Bellomo R, Baldwin I, HaaseFielitz A, et al: Hemodialysis membrane with a high-molecular-weight cutoff and cytokine levels in sepsis complicated by acute renal failure: a phase 1 randomized trial. Am J Kidney Dis 2007;50:296-304. 